\title{
MAPPING GLOBAL OCEAN SURFACE ALBEDO FROM SATELLITE OBSERVATIONS: MODELS, ALGORITHMS, AND DATASETS
}

\author{
Xijia Li, Xianlei Fan, Hongbo Yan, Ang Li, Mengsi Wang, Ying Qu* \\ School of Geographical Sciences, Northeast Normal University, Changchun, China - quy100@nenu.edu.cn
}

ICWG IV/III

KEY WORDS: Albedo, Ocean, BRDF, Remote sensing, Radiative transfer, Surface radiation budget

\begin{abstract}
:
Ocean surface albedo (OSA) is one of the important parameters in surface radiation budget (SRB). It is usually considered as a controlling factor of the heat exchange among the atmosphere and ocean. The temporal and spatial dynamics of OSA determine the energy absorption of upper level ocean water, and have influences on the oceanic currents, atmospheric circulations, and transportation of material and energy of hydrosphere. Therefore, various parameterizations and models have been developed for describing the dynamics of OSA. However, it has been demonstrated that the currently available OSA datasets cannot full fill the requirement of global climate change studies. In this study, we present a literature review on mapping global OSA from satellite observations. The models (parameterizations, the coupled ocean-atmosphere radiative transfer (COART), and the three component ocean water albedo (TCOWA)), algorithms (the estimation method based on reanalysis data, and the direct-estimation algorithm), and datasets (the cloud, albedo and radiation (CLARA) surface albedo product, dataset derived by the TCOWA model, and the global land surface satellite (GLASS) phase-2 surface broadband albedo product) of OSA have been discussed, separately.
\end{abstract}

\section{INTRODUCTION}

Ocean surface albedo (OSA) is one of the important parameters in surface radiation budget (SRB). It is usually considered as a controlling factor of the heat exchange among the atmosphere and ocean (Qu, 2017). The temporal and spatial dynamics of OSA determine the energy absorption of upper level ocean water, and have influences on the oceanic currents, atmospheric circulations, and transportation of material and energy of hydrosphere. Therefore, various parameterizations and models have been developed for describing the dynamics of OSA. However, it has been demonstrated that the currently available OSA datasets cannot full fill the requirement of global climate change studies (Bender, et al., 2006). In this study, we present a review on mapping global OSA from satellite observations. The models, algorithms, and datasets for mapping OSA from satellite observations were discussed in the following sections.

\section{MODELS}

\subsection{Parametrizations}

In the general circulation models (GCMs), the OSA is often described by simple parameterizations or schemes (Briegleb, et al., 1986, Hansen, et al., 1983, Jin, et al., 2004, Jin, et al., 2011, Payne, 1972, Taylor, et al., 1996). In these models, the OSA is usually parameterized with solar zenith angle (SZA) and wind speed. However, the chlorophyll, coloured dissolved organic matter (CDOM), and sediment contents are usually neglected.

\subsection{COART}

The Coupled Ocean-Atmosphere Radiative Transfer (COART) model is established on the coupled discrete ordinate radiative transfer (coupled DISORT). Compared with the widely used DISORT model, there are two main improvements in the
COART model (Jin, et al., 2004, Jin, et al., 2011): (1) The refractive index variation in the medium was considered, and the radiation interactions between atmosphere and ocean were treated as a consistent coupled system; (2) The sun glint effect was considered by the surface slope distribution model which is parametrized with wind speed and direction (Cox and Munk, 1954). In a consequent study, the COART model was further employed for parameterizing the OSA with SZA, wind speed, transmission by atmospheric cloud/aerosol, and ocean chlorophyll concentration.

\subsection{TCOWA}

The three component ocean water albedo (TCOWA) model treats the reflectance of ocean surface as three components (Feng, et al., 2016): water leaving, whitecaps, and sun glints. In this model, the bidirectional reflectance distribution function (BRDF) can be expressed as,

$$
R_{o s}=W R_{e f}+(1-W) R_{g}+\left(1-W R_{e f}\right) R_{w l}
$$

where is $R_{o s}$ the BRDF of ocean water surface, $W R_{e f}$ is the effective reflectance of the total whitecaps over a certain sea surface; $(1-W) R_{g}$ and $\left(1-W R_{e f}\right) R_{w l}$ are the contributions from the sun glint and water-leaving terms, respectively. In this model, the water leaving component was modelled with chlorophyll, CDOM, and sediment contents (Morel and Gentili, 1996); the fraction of whitecaps was modelled with wind speed(Callaghan, et al., 2008, Koepke, 1984); and the sun glints component was modelled based on the Cox-Munk function (Cox and Munk, 1954).

\footnotetext{
* Corresponding author
} 


\section{ALGORITHMS}

The methods for mapping OSA from satellite observations can be categorized to two types: the estimation method based on reanalysis data, and the direct-estimation algorithm.

\subsection{Estimation method based on reanalysis data}

In this method, the OSA can be estimated based on the ocean BRDF models (e.g., COART and TCOWA models) and reanalysis data. The main input parameters of this method are chlorophyll content, wind speed, and wind direction, etc. The ocean colour datasets and reanalysis data generated from satellite observations can be employed for mapping global OSA (Feng, et al., 2016). The flowchart of the estimation method based on reanalysis data is shown in Fig. 1.

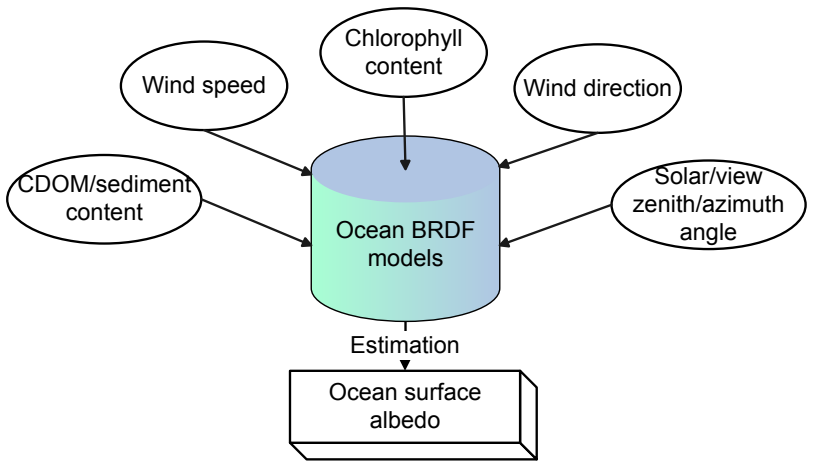

Fig. 1 Flowchart of the estimation method based on reanalysis data

\subsection{Direct-estimation algorithm}

The OSA can also be directly estimated from satellite observations. The so-called direct-estimation algorithm was firstly used for estimating land surface albedo (Qu, et al., 2014). However, the framework of this algorithm is particular suitable for mapping OSA. The flowchart of the direct-estimation algorithm is shown in Fig. 2. First, a BRDF dataset of ocean surface was built based on radiative models. Then, the satelliteobserved top of atmospheric (TOA) reflectance and surface broadband albedo was calculated by atmospheric radiative transfer model and BRDF modelling, separately. Finally, the relationships between the satellite-observed TOA reflectance and surface broadband albedo was established by an angular bin regression method (Qu, 2017, Qu, et al., 2016).

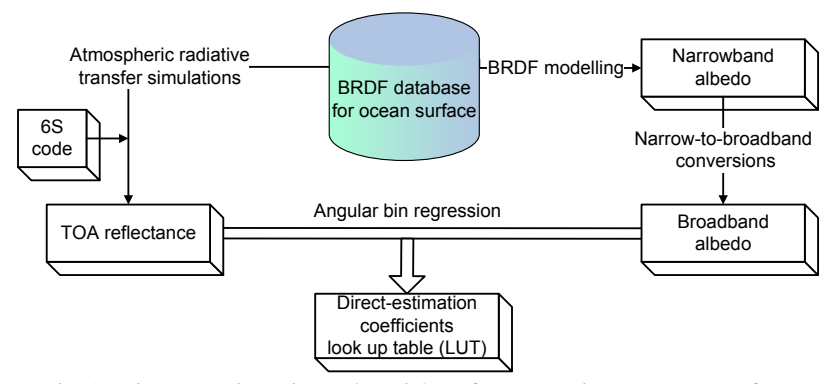

Fig.2 Direct-estimation algorithm for mapping ocean surface broadband albedo

\section{DATASETS}

In recent decades, various land surface albedo (LSA) datasets have been generated from satellite observations $(\mathrm{Qu}$, et al.,
2015), such as, the moderate resolution imaging Spectroradiometer (MODIS) product and the global land surface satellite (GLASS) phase-1 surface albedo product. However, most of these products contain land surface broadband albedo only. Compared with the land surface albedo, OSA was rarely estimated from satellite observations. The current available OSA datasets have been listed in Table 1 .

\begin{tabular}{lllll}
\multicolumn{5}{c}{ Table 1. List of the currently available OSA dataset } \\
\hline Name & $\begin{array}{l}\text { Spatial } \\
\text { coverage }\end{array}$ & $\begin{array}{l}\text { Temporal } \\
\text { span }\end{array}$ & $\begin{array}{l}\text { Spatial } \\
\text { resolution }\end{array}$ & $\begin{array}{l}\text { Temporal } \\
\text { resolution }\end{array}$ \\
\hline $\begin{array}{l}\text { CLARA- } \\
\text { A1 }\end{array}$ & Global & $\begin{array}{l}1982- \\
2009\end{array}$ & $25 \mathrm{~km}$ & $\begin{array}{l}5 \text { days/ } \\
1 \text { month }\end{array}$ \\
TCOWA & $\begin{array}{l}\text { Global } \\
\text { ocean } \\
\text { surface }\end{array}$ & 2011 & $1 \mathrm{~km}$ & daily days \\
& & & & \\
$\begin{array}{l}\text { GLASS } \\
\text { phase-2 }\end{array}$ & Global & $\begin{array}{l}2000- \\
2013\end{array}$ & $\begin{array}{l}1 \mathrm{~km} / \\
0.05^{\circ}\end{array}$ & 8 days \\
\hline
\end{tabular}

\subsection{CLARA}

The cloud, albedo and radiation (CLARA) is a global dataset of cloud properties, surface albedo, and surface radiation products generated by the EUMETSAT satellite application facility on climate monitoring (CM SAF). The CLARA surface broadband albedo product (Riihelä, et al., 2010, Riihelä, et al., 2013) version 1 is a 28 yr (1982-2009) global covered dataset, which was generated from the advanced very high resolution radiometer (AVHRR) data, with a spatial resolution of $25 \mathrm{~km}$, and a temporal resolution of pentad or 1 month. The main generating procedure of CLARA surface albedo products are: data reconstruction, topographic correction, atmospheric correction, angular modelling, and narrow-to-broadband conversion. The OSA can be estimated by a look-up table derived based on the COART model. However, the OSA in CLARA-A1 surface albedo product (Fig. 3) was filled with a constant default value of 0.0676 due to the unavailable of wind speed and chlorophyll data.

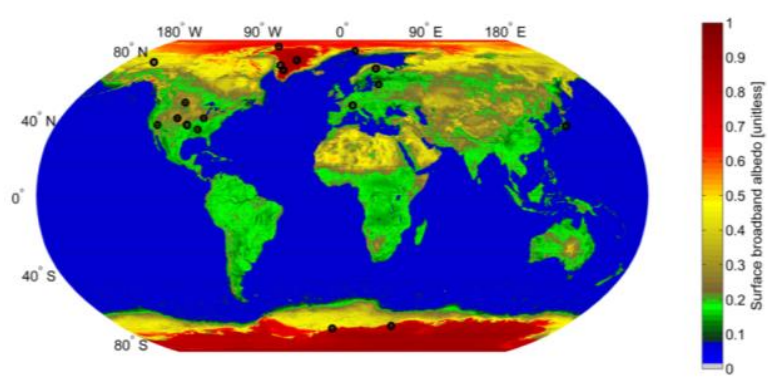

Fig.3. CLARA surface albedo product Average of the monthly-mean CLARA SAL product in 2007.

\subsection{TCOWA}

The TCOWA OSA dataset was generated from the MODIS and the MERRA meteorological reanalysis dataset. The OSA was estimated by the TCOWA model with the input parameters of chlorophyll content, wind speed, and wind direction (Feng, et al., 2016). The results (Fig. 4) show that spatial and temporal dynamics of the OSA can be mapped with the aid of TCOWA model and meteorological reanalysis dataset. 


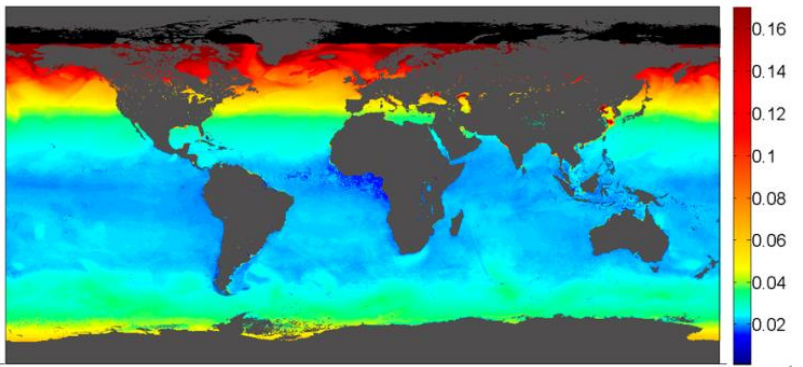

(a)

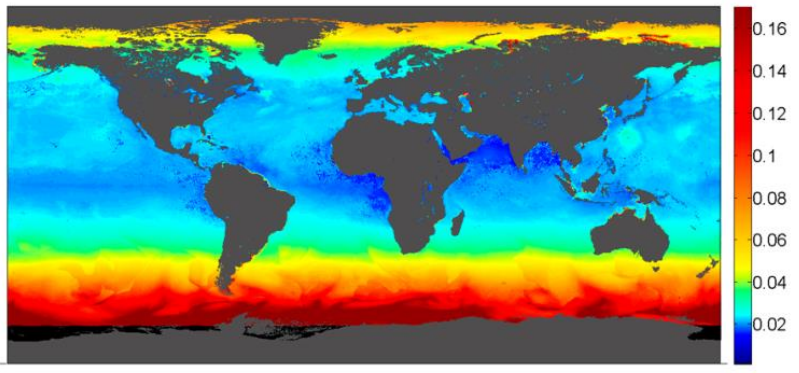

(b)

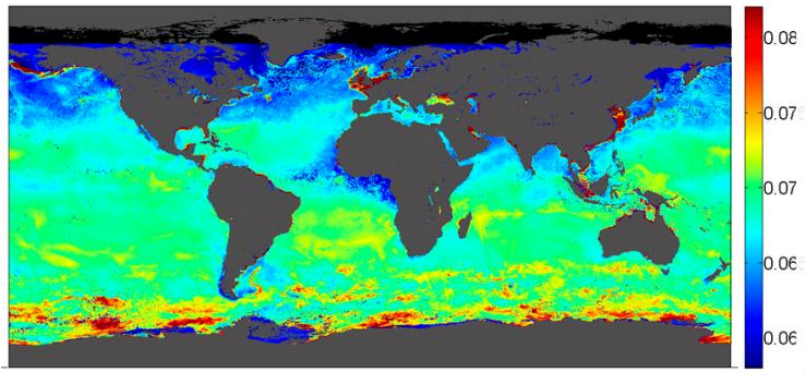

(c)

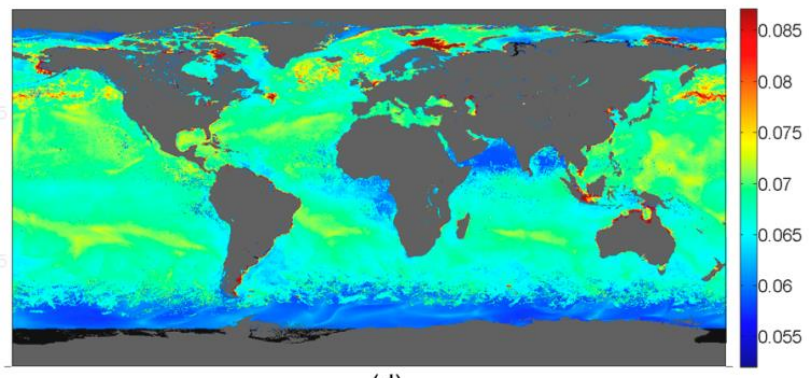

(d)

Fig.4. OSA generated based on the TCOWA model and reanalysis data

Black-sky albedo on Feb. $3^{\text {rd }}$ (a) and Aug. $3^{\text {rd }}$ (b), 2011; Whitesky albedo on Feb. $3^{\text {rd }}$ (c) and Aug. $3^{\text {rd }}$ (d), 2011. SZA more than $88^{\circ}$ is voided and marked in black.

\subsection{GLASS phase-2 product}

The GLASS phase-2 surface broadband albedo product (Qu, et al., 2016) was generated with MODIS data with a spatial resolution of $1 \mathrm{~km}$, and a temporal resolution of 8 day. In the GLASS phase-1 surface albedo product (Liang, et al., 2013, Liu, et al., 2013), it covered land surface only, and left ocean surface as blank. In the GLASS phase-2 surface albedo product, it was further extended to ocean surface. The MODIS top of atmosphere (TOA) reflectance was directly converted to surface broadband (shortwave, near infrared, and visible bands) albedo by the direct-estimation algorithm (DEA)(Qu, et al., 2016, Qu, et al., 2014), and then be filled with a statistical-based temporal filtering (STF) method(Liu, et al., 2013). In the directestimation algorithm, the BRDF dataset of ocean surface was built based on the TCOWA model. Then, the relationships between directional TOA reflectance of MODIS data and surface broadband albedo were established by the angular bin regression method. The three broadband OSA were then estimated directly base on the direct-estimation coefficients. The preliminary results of the GLASS phase-2 global land and ocean surface broadband albedo product are shown in Fig. 5 .

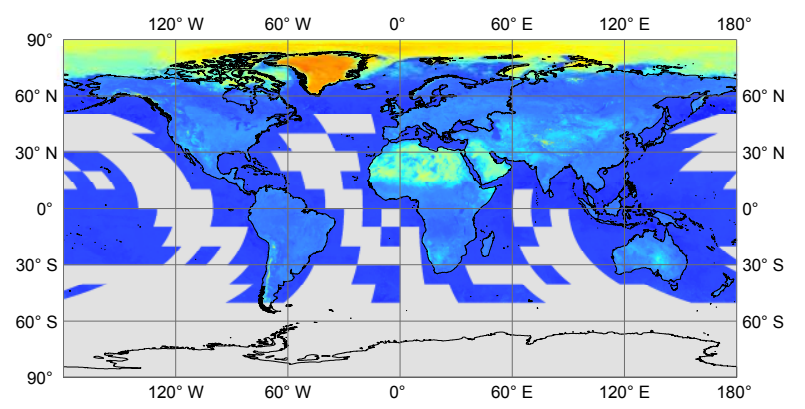

(a)

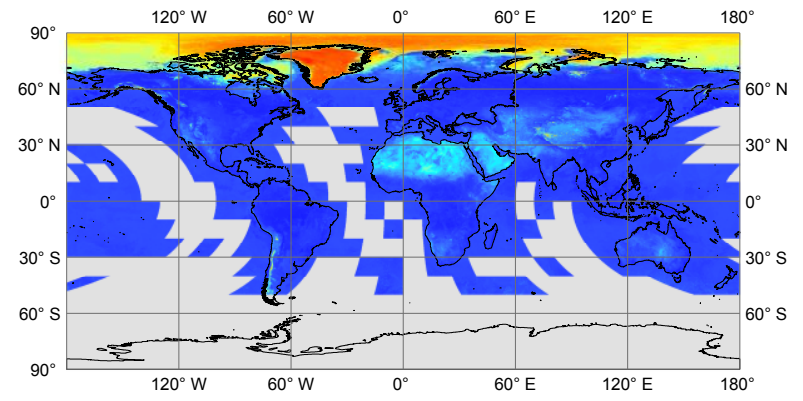

(b)

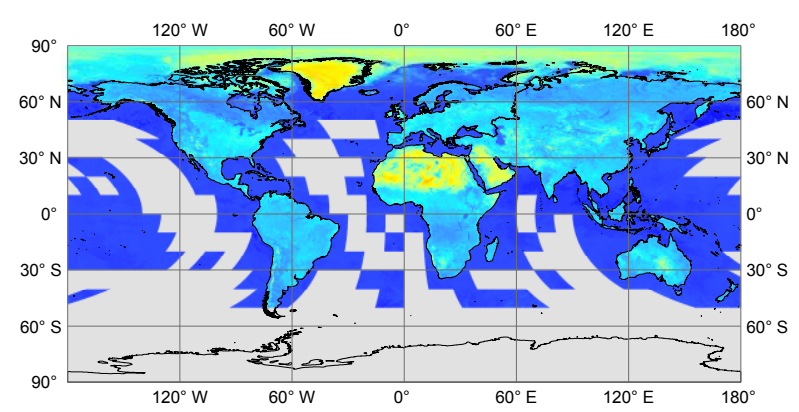

(c)

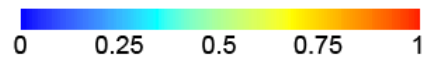

Fig.5. GLASS phase-2 surface broadband albedo product

(a) shortwave, (b) visible, and (c) near infared bands Surface broadband albedo at June 18th, 2007, where the voided value was marked with grey.

\section{CONCLUSIONS}

In this study, we present a review for mapping OSA from satellite observations. Although these methods and datasets are still need to be improved in the future, the preliminary results have shown great advantages for mapping the spatial and temporal dynamics of global OSA from satellite observations. In the SRB and climate change studies, these models and datasets of OSA, e.g., TCOWA model can also be used for 
predicting the ocean albedo changes at different representative concentration pathways (RCPs)

\section{ACKNOWLEDGEMENTS}

This research was financially supported by the National Natural Science Foundation of China (41601349), the Jilin Province's Science and Technology Development Program (20180520220JH), the Fundamental Research Funds for the Central Universities (2412016KJ028), and the Open Funds of State Key Laboratory of Remote Sensing Science (OFSLRSS201624).

\section{REFERENCES}

Qu Y., 2017. Sea surface albedo. in Comprehensive Remote Sensing. vol. 5, S. Liang, Ed. Oxford, UK: Elsevier.

Bender F. A. M., Rodhe H., Charlson R. J., Ekman A. M., and Loeb N., 2006. 22 views of the global albedo-comparison between 20 GCMs and two satellites, Tellus A, 58(3), pp. 320330

Briegleb B., Minnis P., Ramanathan V., and Harrison E., 1986. Comparison of regional clear-sky albedos inferred from satellite observations and model computations, Journal of Climate and Applied Meteorology, 25(2), pp. 214-226.

Hansen J., Russell G., Rind D., Stone P., Lacis A., Lebedeff S., Ruedy R., and Travis L., 1983. Efficient Three-Dimensional Global Models for Climate Studies: Models I and II, Monthly Wather Review, 111(4), pp. 609-662.

Jin Z., Charlock T. P., Smith W. L., and Rutledge K., 2004. A parameterization of ocean surface albedo, Geophysical Research Letters, 31(22), p. L22301.

Jin Z., Qiao Y., Wang Y., Fang Y., and Yi W., 2011. A new parameterization of spectral and broadband ocean surface albedo, Optics express, 19(27), pp. 26429-26443.

Payne R. E., 1972. Albedo of the sea surface, Journal of the Atmospheric Sciences, 29(5), pp. 959-970.

Taylor J., Edwards J., Glew M., Hignett P., and Slingo A., 1996. Studies with a flexible new radiation code. II: Comparisons with aircraft short - wave observations, Quarterly Journal of the Royal Meteorological Society, 122(532), pp. 839-861.

Cox C. and Munk W., 1954. Measurement of the roughness of the sea surface from photographs of the sun's glitter, Journal of The Optical Society of America, 44(11), pp. 838-850.

Feng Y., Liu Q., Qu Y., and Liang S., 2016. Estimation of the ocean water albedo from remote sensing and meteorological reanalysis data, IEEE Transactions on Geoscience and Remote Sensing, 54(2), pp. 850-868.

Morel A. and Gentili B., 1996. Diffuse reflectance of oceanic waters. III. Implication of bidirectionality for the remotesensing problem, Applied Optics, 35(24), pp. 4850-4862.
Callaghan A., de Leeuw G., Cohen L., and O'Dowd C. D., 2008. Relationship of oceanic whitecap coverage to wind speed and wind history, Geophysical Research Letters, 35(23), p. L23609.

Koepke P., 1984. Effective reflectance of oceanic whitecaps, Applied Optics, 23(11), pp. 1816-1824.

Qu Y., Liu Q., Liang S., Wang L., Liu N., and Liu S., 2014. Direct-estimation algorithm for mapping daily land-surface broadband albedo from MODIS data, IEEE Transactions on Geoscience and Remote Sensing, 52(2), pp. 907-919.

Qu Y., Liang S., Liu Q., Li X., and Liu S., 2016. Estimating shortwave Arctic sea-ice albedo from MODIS data, Remote Sensing of Environment, 186(pp. 32-46.

Qu Y., Liang S., Liu Q., He T., Feng Y., and Liu S., 2015. Mapping surface broadband albedo from satellite observations: A review of literatures on algorithms and products, Remote Sensing, 7(1), pp. 990-1020.

Riihelä A., Laine V., Manninen T., Palo T., and Vihma T., 2010. Validation of the Climate-SAF surface broadband albedo product: Comparisons with in situ observations over Greenland and the ice-covered Arctic Ocean, Remote Sensing of Environment, 114(11), pp. 2779-2790.

Riihelä A., Manninen T., Laine V., Andersson K., and Kaspar F., 2013. CLARA-SAL: a global 28 yr timeseries of Earth's black-sky surface albedo, Atmospheric Chemistry and Physics, 13(7), pp. 3743-3762.

Liang S., Zhao X., Yuan W., Liu S., Cheng X., Xiao Z., Zhang X., Liu Q., Cheng J., Tang H., Qu Y. H., Bai Y., Qu Y., Ren H., Yu K., and Townshend J., 2013. A Long-term Global LAnd Surface Satellite (GLASS) Dataset for Environmental Studies, International Journal of Digital Earth, 6, supp1(pp. 69-95.

Liu Q., Wang L., Qu Y., Liu N., Tang H., Liang S., and Liu S., 2013. Preliminary evaluation of the long-term GLASS albedo product, International Journal of Digital Earth, 6, supp1(1), pp. 5-33.

Liu N., Liu Q., Wang L., Liang S., Wen J., Qu Y., and Liu S., 2013. A statistics-based temporal filter algorithm to map spatiotemporally continuous shortwave albedo from MODIS data, Hydrology and Earth System Sciences, 17(6), pp. 21212129. 